\title{
O ESPAÇO COMO SISTEMA DE VALORES: UMA CONTRIBUIÇÃO À EPISTEMOLOGIA DA GEOGRAFIA ${ }^{1}$
}

\author{
Cláudio Smalley Soares Pereira ${ }^{2}$ \\ João César Abreu de Oliveira ${ }^{3}$
}

\section{Resumo}

O espaço foi e é um objeto de estudo de várias áreas do saber, tendo ele um caráter polissêmico. No decorrer do processo histórico, várias foram as definições que o espaço recebeu, quando não só a Geografia, como também a Sociologia, a Antropologia e a Filosofia lhe deram significados diferentes. No campo teórico-epistemológico da Geografia, várias foram as conceituações sobre o espaço, desde a concretização da Geografia como ciência no século XIX até chegar à atualidade, em que o debate permanece na tentativa de compreensão e análise da sociedade contemporânea. No presente texto, trabalhar-se-á com a hipótese do espaço como um sistema de valores, tendo como base teórica a contribuição das correntes do pensamento geográfico para propor uma nova via teórica para o estudo do espaço, e, com isso, contribuir teoricamente para a construção de uma teoria do espaço geográfico.

Palavras-chave: Geografia. Epistemologia. Teoria do Espaço. Sistema de Valores.

\begin{abstract}
The space has been an object of study for some areas of knowledge, taking it a polysemic character. During historical process, several definitions were arisen, where not only Geography, as well as, Sociology, Anthropology and Philosophy has given different meanings for it. In the field theoreticalepistemological of Geography, several have been the conceptualizations about the space, since the achievement of Geography as science in nineteenth century until arriving at the present time, where the discussion remains in the attempt to understand and analyze the contemporary society. In the present text, it will be worked the hypothesis of the space as a system of values, taking as theoretical base the contribution for geographic thought line to consider a new theoretical way for the study of the space, this is, to contribute theoretically for the construction of a theory of geographic space.
\end{abstract}

Keywords: Geography. Epistemology. Theory of Space. System of Values.

\section{INTRODUÇÃO}

Pensar sobre o espaço foi e ainda é uma tarefa cara para as ciências humanas e sociais, sobretudo para a Geografia, a qual tem como foco principal de seus estudos o espaço geográfico. Há decênios (não seria exagero dizer que há mais de um século), os geógrafos se debruçam para construir uma teoria do espaço a fim de dar conta do devir da realidade social.

A proposta que ora apresentamos é oferecer elementos para o debate sobre o espaço no intuito de acolher as contribuições das correntes do pensamento geográfico e explicitar a

\footnotetext{
${ }^{1}$ Trabalho realizado a partir das discussões sobre o conceito de espaço no Grupo de Pesquisa Geografia, Meio Ambiente e Cidadania (GEOMAC), cadastrado no CNPq. Agradecemos a leitura crítica e sugestões feitas pela prof ${ }^{a}$. Ms. Ilaina Damasceno Pereira, cujas observações foram importantes para o melhoramento do trabalho.

${ }^{2}$ Graduando em Geografia pela Universidade Regional do Cariri - URCA/CE e Bolsista de IC do CNPq. E-mail: clasmalley@hotmail.com

${ }^{3}$ Professor Doutor do Departamento de Geociências da Universidade Regional do Cariri - URCA/CE e IFCE - Crato Ceará, líder do Grupo de Pesquisa Geografia, Meio Ambiente e Cidadania (GEOMAC). E-mail: njcesar@bol.com.br
} 
possibilidade de uma análise geográfica da sociedade e do ser humano pelo ângulo espacial, sem dicotomizar a ciência geográfica.

Nossa preocupação para a elaboração de tal estudo decorre de existirem na atualidade várias e diferentes correntes que versam sobre o espaço geográfico, possuindo cada qual um método específico e próprio, baseado em escolas filosóficas e orientações metodológicas diferentes/divergentes. Assim não se pretende unificar as "geografias", mas reconhecer as contribuições das diferentes correntes e, a partir delas, propor uma via alternativa de se pensar o espaço geográfico.

Deste modo, a reflexão pretende fomentar ainda mais o debate acerca do conceito de espaço, contemplando o plano teórico e mostrando que a Geografia é uma ciência em constante dinâmica, em que o debate sobre o espaço como objeto e conceito chave está longe de ser encerrado.

Portanto, apresentamos nesse ensaio outra via para se pensar o espaço geográfico, proporcionando uma discussão sobre a validade teórica da proposta, mas tendo em vista a dinamicidade do espaço, o qual, observado pelo viés da ciência geográfica, está em constante transitoriedade, exigindo, dessa forma, um constante (re)pensar espacial de acordo com a realidade que circunda o olhar geográfico.

\section{O PONTO DE PARTIDA}

O espaço, juntamente com o tempo, é categoria fundamental da existência humana: um não existe sem o outro. O espaço é construído no devir histórico, no processo de produção material e imaterial e na reprodução da vida humana.

$\mathrm{Na}$ história do pensamento geográfico, vários conceitos (dentre eles os de paisagem, território, lugar, ambiente, meio) foram formulados na tentativa de entender os processos que se manifestavam na superfície da terra, na perspectiva de tornar o mundo mais inteligível e palpável pela/para a sociedade.

O espaço é um desses conceitos que passaram, ao longo da história da ciência geográfica, por várias reformulações e reconceituações, de acordo com o período que se queria analisar.

No presente ensaio, apresentamos uma hipótese que tentará ser aprofundada no decorrer do estudo, tomando como ponto de partida para investigação a afirmação de que $o$ espaço é, também, um sistema de valores. As chaves teóricas para a comprovação de tal 
hipótese serão expostas no decorrer do texto a partir das concepções espaciais de autores como Harvey (1980), Lefebvre (2006, 2008a, 2008b, 2008c), Moraes e Costa (1984 e 1988), Moraes (2002) e Santos (2006, 2008a, 2008b, 2008c), entre outros. Sabedores das dificuldades teóricas e epistemológicas que fazem parte da reflexão em torno do conceito de espaço geográfico, faremos algumas explanações a respeito da contribuição de alguns autores clássicos ${ }^{4}$ da Geografia e da história do pensamento geográfico para nos dar um suporte conceitual e teórico, na tentativa de confirmar nossa proposta.

\section{A POLISSEMIA DO ESPAÇO}

Tornou-se corriqueiro usar a palavra espaço para designar várias coisas, seja nas universidades, no trabalho, no lazer, na escola, enfim, na vida cotidiana. Expressões como espaço virtual, espaço físico, espaço escolar, espaço social, espaço domiciliar, espaço matemático, espaço público, espaço privado e uma infinidade de outros espaços têm se tornado frequentes nas falas dos atores sociais. No processo histórico, a palavra espaço teve diversos significados em vários períodos, cada um buscando uma operacionalidade diferente para a mesma expressão.

Os filósofos gregos foram os pioneiros na reflexão acerca do espaço. Pitágoras, Platão e Aristóteles são exemplos de pensadores desse período que buscaram entendê-lo. Eles tinham a concepção de espaço em termos conceituais abstratos. Platão considerou o espaço apenas como o substrato material, reduzindo-o apenas ao palpável, enquanto Aristóteles o comparou a um campo de forças, um acidente da matéria. Para ambos, espaço e matéria são inseparáveis. Assim, para os dois filósofos "a Geometria é a cola que une espaço e matéria. A Geometria é explicitamente uma abstração dos corpos físicos reais, ao mesmo tempo em que descreve a estrutura do espaço" (SMITH, 1988, p. 114). As concepções desses filósofos foram um dos alicerces da origem do conhecimento geográfico, juntamente com as idéias desenvolvidas por outros pensadores e povos (Fenícios, Babilônios, Egípcios etc.) $)^{5}$.

No período renascentista, o espaço passou a ser pensado de um ponto de vista racionalista, tendo como base as concepções da filosofia cartesiana. No final do século XVII e início do século XVIII, as concepções de Newton a respeito do espaço, tratando-o como ente

\footnotetext{
${ }^{4} \mathrm{O}$ sentido da palavra clássico expressa aqui diz respeito aos autores que deram uma fundamental contribuição à teoria da Geografia recentemente, ou seja, os já consolidados como teóricos da ciência geográfica, e não se refere aos autores da denominada "Geografia Clássica" da dicotomia determinismo x possibilismo.

${ }^{5}$ Lencioni (1999) explicita as importantes contribuições dos Gregos, Fenícios, Babilônios, Egípcios, Árabes e outros para a construção do conhecimento geográfico.
} 
absoluto, uma entidade independente da matéria, romperam com as concepções anteriores de espaço que o confundiam com os eventos materiais (SMITH, 1988). No século XVIII, as idéias de Kant e suas críticas às concepções racionalistas e empiristas (bases do pensamento Iluminista) deram novos contornos à categoria espaço. Este pensador afirmou que "o fundamento da Geografia é o espaço" (LENCIONI, 1999, p. 78).

Na Sociologia, a palavra espaço já vem sendo discutida desde o final do século XIX. Teria sido Durkheim quem criou o termo espaço social, diferenciando-o do espaço físico (SMITH, 1988), distinção essa muito utilizada ainda hoje pelos sociólogos. Bourdieu (2003) e Goffman (FREHSE, 2008), por exemplo, utilizam das concepções de espaço social e espaço físico em suas análises. Cabe destacar dentre os sociólogos a obra de Lefebvre ${ }^{6}$ (2006, 2008a, 2008b, 2008c) sobre a questão do espaço como um produto construído pela sociedade ao longo do processo de reprodução das relações de produção (voltaremos mais adiante a falar mais sobre a contribuição deste pensador). Na Antropologia, Augé (2001) faz uma importante reflexão no sentido de se pensar o espaço na atualidade, período que ele denomina de supermodernidade.

É importante frisar que o espaço, enquanto objeto de reflexão, como já foi visto nas linhas anteriores, não é exclusividade da Geografia, até porque esta, enquanto ciência, será institucionalizada apenas no final do século XIX. Dessa forma, várias são as áreas do conhecimento que se inserem dentro do debate e da reflexão teórico-epistemológica sobre o espaço. Nesse sentido, o espaço discutido pela Geografia é o espaço geográfico.

O debate sobre o espaço e sua teoria emana de uma multiplicidade de disciplinas, dando-lhe cada uma um significado específico e interpretando-o através de orientações filosóficas diferentes. Assim, o debate perdura até o atual momento histórico, quando várias transformações nas diversas esferas sociais acontecem, produzindo cada vez mais elementos e pistas para a constante reflexão sobre o espaço e o seu papel na História. Assim, acreditamos que "a história do espaço (como a do tempo social) está longe se ser esgotada" (LEFEBVRE, 2006, p. 10).

\section{O ESPAÇO NA/DA GEOGRAFIA}

Desde sua fundação como ciência no século XIX, a Geografia desenvolveu significativamente suas concepções teóricas. A dicotomia, entre o que se convencionou

\footnotetext{
${ }^{6}$ Henri Lefebvre é filósofo de formação, graduando-se em 1920. Doutorou-se em Sociologia em 1954.
} 
chamar de "determinismo ratzeliano" e o "possibilismo lablacheano", no fim do século XIX e início do século XX, foi um primeiro enfoque teórico e conceitual sobre o papel da Geografia na sociedade e sobre o seu objeto (o espaço), originando, a partir daí, as primeiras discordâncias entre escolas geográficas diferentes, nesse caso, a alemã e a francesa.

Da sua autonomia como ciência até os anos 1960, a Geografia foi embasada pelo método positivista, pensando a realidade a partir da descrição. Na década de 1960, a "revolução quantitativa" engendra uma nova concepção de espaço na Geografia, baseado na linguagem matemática e no método neopositivista, tendo como formas de pensar a realidade a indução e a dedução. Tipologias, leis, hipóteses e a apreensão lógico-formal da realidade foram as principais características dessa corrente, expressa, sobretudo, no trabalho de Schaefer (1977).

Segundo Santos (2006), o pecado maior do horizonte lógico-formal da Geografia Quantitativa (ou Teorética) foi o de desconsiderar o fator tempo como fundamental para o conhecimento e o entendimento do espaço produzido. O rigor científico só poderia ser alcançado, dessa forma, por uma ciência que tivesse como pressupostos teóricos os métodos físico-matemáticos exatos, quantificados, expressos através dos números.

No início do século XX, mais precisamente na década de 1920, surge nos Estados Unidos a Escola de Berkeley de Geografia Cultural, onde os trabalhos de Carl Sauer foram os pioneiros na abordagem culturalista na Geografia. Suas abordagens foram bastante criticadas devido ao caráter descritivo e ao apego ao positivismo enquanto método (COSGROVE, 2004; e DUNCAN, 2004), privilegiando a aparência dos lugares e "desprezando" o conteúdo social contido nos espaços. Nessa escola a paisagem era o principal conceito trabalhado. Posteriormente, a partir do final das décadas de 1970 e 1980, a Geografia Cultural passou por um processo de renovação, mas somente nos anos 1990 é que ela se tornou efetivamente renovada (CORRÊA; ROSENDAHL, 2007).

A renovação da Geografia Cultural acontece a partir do momento em que uma nova via de reflexão sobre o espaço se abre, pautado na filosofia fenomenológica dos trabalhos de Hurssel, Heidegger, Marleau-Ponty e Sartre. Essa influência pode ser encontrada nos estudos desenvolvidos por Buttimer (1985) e Tuan (1983, 1985). No entanto é somente nas décadas de 1980 e 1990 que essa "geografia fenomenológica" vai ganhar maior notoriedade no mundo acadêmico.

No final da década de 1960 e início de 1970, um movimento diferente nas ciências sociais acaba por engendrar uma nova forma de pensar a realidade, influenciando também a 
Geografia e o pensar sobre o espaço. Trata-se do materialismo histórico-dialético, que é adotado pelas ciências sociais e pela Geografia como via de condução para a análise e interpretação da realidade social.

Nesse período, a Sociologia tem um papel importante para a reflexão em torno do espaço. São os trabalhos de marxistas, sobretudo Castells (2000) e Lefebvre (2006, 2008a, 2008b, 2008c) que vão repercutir como um todo no debate da Teoria do Espaço. Na Geografia, o trabalho pioneiro de Harvey (1980) engrossou o debate, incluindo-a nas reflexões sobre a materialidade do espaço.

Para Harvey (1980), o espaço deve ser compreendido como prática social. Assim, ele mesmo pode ser conceituado através de três perspectivas distintas, que ora podem aparecer isoladas, ora podem se relacionar, e, por isso, não são mutuamente excludentes. O espaço absoluto, o espaço relativo e o espaço relacional, apresentados por Harvey, são os conceitos que se referem à natureza do espaço como prática social.

O trabalho de Soja (1993) é singular no que diz respeito à incorporação do marxismo na Geografia. Segundo o autor, a História sempre foi privilegiada nos estudos e o tempo foi a categoria essencial da Teoria Social Crítica, tratado como fluxo, vivo, móvel. Por outro lado, o espaço sempre foi considerado como uma "complicação desnecessária", tratado como fixo, morto, imóvel. Deste modo, Soja constrói um sistema de idéias pautado no marxismo ocidental, tomando como base teórica para a "reafirmação do espaço na Teoria Social Crítica" as reflexões propostas por Henri Lefebvre, David Harvey, Michael Foucault e outros estudiosos. O resultado de sua reflexão pode ser sintetizado através da relação trialética entre espaço, tempo e ser, onde é possível analisar os processos sociais do mundo atual partindo de uma concepção de que a sociedade e o espaço interagem simultaneamente, a partir de uma dialética sócioespacial. Assim, as "Geografias pós-modernas” aparecem no cenário mundial da Teoria Social Crítica.

É importante notar que as influências externas sempre foram marcantes na construção de conceitos para a Geografia. No entanto, Santos (2008a) alerta que a Geografia precisa construir seus conceitos de dentro, pois sempre que uma ciência toma de outras concepções conceituais emprestadas, estas servem apenas de metáforas, e as metáforas não conseguem tornar o mundo inteligível. Dessa forma, não é demais lembrar que "este espaço - o espaço geográfico - é mais que o espaço social dos sociólogos [e mais que o espaço distância dos economistas] porque também inclui a materialidade" (SANTOS, 2008a, p. 294). Os trabalhos 
de Corrêa $(1988,2007)$ são de grande importância para o entendimento das concepções do espaço dentro da ciência geográfica.

As reflexões desses autores e de tantos outros fizeram que a Geografia conquistasse, nas últimas décadas do século $\mathrm{XX}$, um lugar dentro da Teoria Social, pois ela passou a desenvolver reflexões dentro dos anseios que as concepções e orientações filosóficas "exigiam" para a análise da sociedade, do homem e do espaço em suas processualidades.

\section{AS “GEOGRAFIAS" HUMANISTA E RADICAL: EM BUSCA DE UMA TEORIA DO ESPAÇO ATRAVÉS DA CATEGORIA VALOR}

A produção teórica na/da Geografia sobre o espaço alcançou nas últimas três décadas do século XX um importante patamar dentro das ciências sociais, sobretudo através da chamada "Geografia Radical" e de sua orientação marxista, que polemizou e fez severas críticas às concepções formuladas pela "Geografia Quantitativa" e pela "Geografia Humanista". O problema é que os geógrafos radicais desconsideraram as produções teóricas dessas outras duas "geografias", tendo em vista que as concepções radicais do espaço e a forte influência marxista nos escritos desse período não aceitavam (será que aceitam hoje?) uma concepção imaterial, simbólica, subjetiva e individualizada (não individualista) do espaço. $\mathrm{O}$ que importava para eles (e talvez ainda importe) é apenas o espaço enquanto materialidade, objetividade.

Faz-se importante observar que os radicais e os humanistas formaram um grande "campo de batalha teórico" entre si, acusando e procurando refutar cada vez mais as teorias contrárias às suas matrizes filosóficas e teórico-metodológicas. Isso é bem notório na passagem abaixo:

Todos esses estudos [humanísticos] revelam diversas modalidades de interesse pelo homem, na sua qualidade de indivíduo, mas raramente concluem por fazer proposições concretas e viáveis em vista de uma mudança social que possa assegurar a chegada de uma nova situação. Pode-se dizer que, em sua maioria, eles não ultrapassam o plano dos votos piedosos; ou que seu interesse humano é apenas literário. Também se poderia criticá-los pela falta de coerência filosófica que a abundância e o amontoado de citações só faz tornar mais clara. Trata-se de um humanismo sem o homem verdadeiro e total, de uma moralidade sem conseqüência política. O discurso epistemológico correspondente é freqüentemente confuso e a escolha das bases filosóficas de discussão é parcial. Ensaios mais bem construídos,

\footnotetext{
${ }^{7}$ Preferiu-se usar o termo "Geografia Radical" em vez de "Geografia Crítica", por entendermos que o termo "Crítica" é bem mais amplo, e que a incorporação da fenomenologia - tanto quanto o marxismo - à Geografia também se constitui como um momento de questionamentos e críticas aos pressupostos precedentes. A Geografia Humanista também fez críticas intensas aos pressupostos quantitativistas.
} 
como os de Buttimer, poderiam tirar mais partido do enfoque fenomenológico para mostrar como "o dinamismo do mundo vivo" depende de um processo que vai, incessantemente, da sociedade ao espaço e vice-versa. Mas, o encasulamento nas idéias de Heidegger acarreta uma concepção individualista e idealista, cujo resultado mais claro é o de substituir a práxis coletiva por uma práxis individual, suprimindo, assim, a possibilidade de captar o movimento da sociedade e do espaço como dois dados contraditórios e, ao mesmo tempo, complementares. (SANTOS, 2005, p. 128).

Essa longa citação, que consiste em uma crítica de um marxista às formulações humanistas, expressa de forma clara a disputa teórica na geografia e as constantes críticas e tentativa de refutações de teorias que não condizem com as perspectivas adotadas pelos defensores do marxismo na ciência geográfica. Nesse sentido, a "Geografia Humanista", conforme destacou Duarte e Matias (2005), aparece na teoria geográfica como "uma pedra no sapato" da "Geografia Radical".

Mesmo sabendo dessa "guerra teórica", não pretendemos aqui defender ou acusar uma ou outra corrente de pensamento de seus "erros" e "acertos", e sim buscar o essencial de cada proposta ao colocar que a inserção da categoria valor na conceituação do espaço geográfico (discutido na seção seguinte) pode de alguma maneira avançar na discussão conceitual do espaço a partir das várias concepções existentes, proporcionando, nesse sentido, uma contribuição para a construção da teoria do espaço geográfico.

Esboçaremos, assim, algumas concepções de espaço e tentaremos relacioná-las na tentativa de corroborar a nossa hipótese do espaço ser, também, um sistema de valores. Não discutiremos sobre o conceito valor, pois ele já foi bastante discutido em Moraes e Costa (1984), mas tomemos deles as concepções de valor contido e de valor criado, ou, dito de outra forma, valor do espaço e valor no espaço, para subsidiar a nossa proposta.

\section{O ESPAÇO COMO UM SISTEMA DE VALORES?}

Nessa seção esboçaremos a contribuição dos autores que fazem parte do nosso referencial teórico, na tentativa de corroborar nossa proposta do espaço como sendo um sistema também de valores. Reconhecemos que os pensadores aqui abordados, mesmo sendo todos marxistas, partem de pressupostos distintos. No entanto, um diálogo entre as concepções desses pensadores é de imprescindível importância para construir a nossa proposta teórica.

As categorias valor de uso e valor de troca foram trazidas para a análise do espaço a partir dos estudos da economia política. Desde os trabalhos de Adam Smith, o valor vem 
sendo tratado nessa dupla acepção: uso e troca. No século XIX, Marx deu uma importante contribuição para o debate sobre a categoria valor, tomando-as como uma relação dialética, em que o valor de uso e o valor de troca não existem por si sós: apenas por sua acepção relacional entre si e com outros conceitos é que, segundo Marx, o valor de uso e o valor de troca podem sem entendidos (HARVEY, 1980; MORAES; COSTA, 1984).

O valor de uso é de fundamental importância para a argumentação aqui exposta, uma vez que o espaço deve ser entendido não só como valor de troca, comercial (mercadoria) e objetividade, mas também como valor de uso, subjetivo a cada um dos indivíduos. Dessa forma:

A expressão "valor de uso" pode, assim, ser aplicada a toda classe de objetos, atividades e eventos em situações particulares sociais e naturais. Pode referir-se à ideologia religiosa, instituições sociais, trabalho, linguagem, mercadorias, recreação etc. (HARVEY, 1980, p. 132).

A respeito dessa dupla acepção do valor, Moraes e Costa (1984) dão uma importante contribuição para o estudo do espaço. Para os autores, o espaço foi valorizado a partir de duas concepções distintas: a concepção naturalista e a empirista, tratando o espaço como um valor a priori da sociedade; e a segunda concepção como econômica, que trata o valor a posteriori. Assim, os autores rompem com a dicotomia e unificam as duas concepções a partir da criação dos conceitos de valor do espaço e valor no espaço.

Como na década de 1980 os estudos eram voltados mais para a influência marxista, a valorização do espaço foi tida fundamentalmente como valorização capitalista. Apesar de o estudo de Moraes e Costa (1984) demonstrar a valorização do espaço com um maior enfoque na valorização capitalista, eles fazem referência ao espaço num processo de valorização subjetiva e abrem as vias para a construção de uma teoria que abarque o espaço como um sistema de valores.

É preciso considerar que o espaço sempre foi valorizado pelas diversas sociedades em diversos tempos históricos. Cada sociedade valorizou seu espaço de um modo diferente.

$\mathrm{Na}$ atualidade, o espaço é valorizado de diversas maneiras, tanto do ponto de vista subjetivo como do ponto de vista objetivo. Se tomarmos um determinado espaço como exemplo, veremos que ele pode conter valores que ultrapassam a mera questão monetária, abarcando uma série de contextos que envolvem a cultura e a política (MORAES, 2002).

Nesse sentido cabe colocar o que seria o valor do espaço e o valor no espaço. $\mathrm{O}$ primeiro refere-se à questão do valor no que diz respeito aos recursos naturais que podem ser apropriados pelo homem através do trabalho para realização da vida. É um valor prévio, um 
valor contido; já o segundo é o valor que é agregado ao espaço, quando ele ganha um sentido através da valorização econômica, isto é, um valor de troca, substrato para a realização da vida, um valor criado $^{8}$ (MORAES; COSTA, 1984).

É na dialética e no jogo complexo entre valor do espaço (valor contido) e valor no espaço (valor criado) que as primeiras pistas para se pensar o espaço como um sistema de valores podem ser encontradas. Assim:

\begin{abstract}
é preciso considerar que o espaço terrestre, mesmo quando ainda intocado pela ação humana, possui um certo valor potencial, um volume variável de recursos que podem ser apropriados pelo homem para a produção de suas condições de existência. À medida que a sociedade cria formas materiais que se fixam ao solo (estradas, edifícios, fábricas, etc.) ocorre uma agregação de valor ao espaço, a qual tende a prosseguir mesmo depois que o substrato natural já foi transformado pelo trabalho humano, com um acúmulo constante de valor (DINIZ FILHO, 1999, p. 179).
\end{abstract}

Poder-se-ia até pensar o seguinte: mas, nesse caso, o espaço terrestre que contém o valor antes da ação do trabalho humano não é a natureza? A natureza, assim, seria sinônimo de espaço ${ }^{9}$ ? Não cabe aqui entrar em detalhes sobre a diferenciação conceitual dos dois termos, mas cabe lembrar que a intencionalidade das ações humanas torna a natureza "desnaturalizada" antes mesmo das ações se materializarem. Isto é, a natureza deixa de ser natureza quando o ser humano, através de suas intenções (e não necessariamente ações propriamente ditas, as quais vêm depois) a vê como um valor, como um objeto, ou uma mercadoria. Nesse contexto, a contribuição de Santos (2008a) sobre a intencionalidade das ações, relacionado-a com a psicosfera e a tecnosfera, é de grande importância teórica para entender esse questionamento.

A concepção de Santos (2008a) sobre o espaço é uma das mais abrangentes dentro da ciência geográfica, aparecendo aqui como um referencial teórico de suma importância para nossas pretensões. Vejamos a sua elaboração teórica:

O espaço é formado por um conjunto indissociável, solidário e também contraditório, de sistemas de objetos e sistemas de ações, não considerados isoladamente, mas como um quadro único no qual a história se dá. No começo era a natureza selvagem, formada por objetos naturais, que ao longo da história vão sendo substituídos por objetos fabricados, objetos técnicos, mecanizados e, depois cibernéticos fazendo com que a natureza artificial tenda a funcionar como uma máquina (SANTOS, 2008a, p. 63).

\footnotetext{
${ }^{8} \mathrm{O}$ valor criado pode ser também cultural e político, uma vez que o processo de valorização do espaço ultrapassa as barreiras econômicas.

${ }^{9}$ Para Santos (2008b) a natureza segunda, nos moldes de Marx, trabalhada e modificada pelo trabalho humano é sinônimo de espaço. No entanto, a primeira natureza não. Ela é condição para que o espaço exista.
} 
Essa é uma das chaves teóricas para a nossa proposta. Entendemos que, ao mesmo tempo em que ações e objetos interagem de forma mútua e simultânea a esses objetos e a essas ações, são produzidos valores que fazem parte do processo de produção espacial. Os Shoppings Centers servem de exemplo, pois, ao se instalarem em determinado espaço da cidade, elevam o preço do solo urbano nas suas proximidades, aumentando a especulação imobiliária e produzindo novas formas de habitação e consumo. Por outro lado, o que dizer do espaço sagrado do Santuário de Aparecida em São Paulo? Aqui o valor agregado ao espaço é diferente, é concebido como um valor religioso, cultural, um espaço repleto de significados para os fiéis que anualmente visitam o Santuário. Em outras palavras, os objetos geográficos contêm valores que podem mudar de acordo com a situação e com os interesses dos atores sociais.

O espaço é um conjunto interdependente entre ações, objetos e valores, relacionandose mutuamente. A valorização do espaço é uma ação (ou conjunto de ações) protagonizada dialeticamente e contraditoriamente por vários atores sociais (Estado, empresas, Igreja, promotores imobiliários, movimentos sociais etc.), com interesses diversos no processo de produção ${ }^{10}$ do espaço, fazendo com que ele seja também um sistema de valores.

Em outro trabalho, Santos (2008c) coloca que o espaço também pode ser entendido como configuração territorial e dinâmica social impresso e materializado na paisagem. Nesse sentido, a paisagem é um dos componentes do espaço geográfico, podendo ser analisada como possuidora de um valor que é agregado a ela. Noutra perspectiva, os estudos de Cosgrove (2004) e Duncan (2004) mostram o papel da paisagem e o seu significado, ou seja, o seu valor cultural, o discurso ideológico e o poder na construção dos espaços.

No entanto, paisagem não é espaço. A paisagem é um dos componentes do espaço, sua esfera visível. Assim, é na distinção conceitual entre paisagem e espaço feita por Santos (2008a) que a nossa proposta apresenta coerência conceitual e uma fundamentação teórica consistente. O autor deixa bem claro que o espaço é também um sistema de valores ${ }^{11}$ que está em constante transformação.

A paisagem se dá como um conjunto de objetos reais-concretos. Nesse sentido a paisagem é transtemporal, juntando objetos passados e presentes, uma construção transversal. O espaço é sempre um presente, uma construção horizontal, uma situação única. Cada paisagem se caracteriza por uma dada distribuição de formas-

\footnotetext{
${ }^{10}$ No que se refere ao conceito de produção, ver a análise de Godoy (2008) sobre a teoria da produção do espaço de Henri Lefebvre.

${ }^{11}$ Para Santos (2008), o espaço como sistema de valores é, sobretudo, econômico; mas como pretendemos a totalidade do processo de produção espacial, o sistema de valores pode ser interpretado levando-se em consideração o espaço não só em sua dimensão econômica, mas também política e cultural.
} 
objetos, providas de um conteúdo técnico específico. Já o espaço resulta da instrução da sociedade nessas formas-objetos. Por isso, esses objetos não mudam de lugar, mas mudam de função, isto é, de significação, de valor sistêmico. A paisagem é, pois, um sistema material, nessa condição, relativamente imutável: o espaço é um sistema de valores, que se transforma permanentemente (SANTOS, 2008a, p. 103104). (grifo nosso).

O valor é intrínseco ao espaço. Isto é, o espaço é um produto (obra e mercadoria) social e histórico, dotado de significados e significações, ou seja, valores. Não há espaço insignificante. O seu valor não é percebido apenas enquanto resultado (espaço-produto), mas também no próprio processo de produção espacial (espaço-condição e espaço-meio). Dessa forma, "sendo o espaço (e tudo o que ele contém) uma condição universal e preexistente do trabalho, ele é, desde logo, um valor de uso, um bem de utilidade geral" (MORAES; COSTA, 1984, p. 123). (Grifos do autor).

Para dar mais vigor e concretude à nossa proposta, é importante ressaltar a análise pioneira de Lefebvre (2006, 2008a, 2008b, 2008c) sobre a produção do espaço e as questões relacionadas ao espaço como valor de uso e valor de troca.

Henri Lefebvre foi um filósofo e sociólogo de orientação marxista, mas era detentor de um pluralismo teórico-metodológico que fez com que sua produção intelectual rompesse com as barreiras do marxismo ortodoxo e vulgar. A sua análise sobre a produção do espaço foi fundamental para a construção de uma teoria do espaço que abarcasse a totalidade, desvelando o processo de produção do espaço e suas características relacionadas ao valor de uso e ao valor de troca. O seu pensamento compõe uma das chaves teóricas para a nossa argumentação.

É necessário entender o conceito de produção lefebvriano, que ultrapassa a concepção simplista e reducionista de produção material. O seu conceito de produção envolve todas as relações que constituem o processo produtivo em geral. Dessa forma:

(...) a dupla acepção do termo decorre de que 'os homens' em sociedade produzem ora coisas (produtos), ora obras (todo o resto). As coisas são enumeradas, contadas, apreciadas em dinheiro, trocadas. E as obras? Dificilmente. Produzir, em sentido amplo, é produzir ciência, arte, relações entre seres humanos, tempo e espaço, acontecimentos, história, instituições, a própria sociedade, a cidade, o Estado, em uma palavra: tudo. A produção de produtos é impessoal; a produção de obras não se compreende se ela não depende de sujeitos (LEFEBVRE, apud GODOY, 2008, p. 126).

Assim, o espaço é produzido no processo histórico enquanto coisa e enquanto obra. Dessa forma, conforme aponta Santos (2006, p. 203), "o ato de produzir é, ao mesmo tempo, o ato de produzir espaço". É nesse sentido que o tratamento do espaço como sistema de 
valores ganha força, pois ele, o espaço, é um produto sócio-cultural que é valorizado enquanto troca e enquanto uso. Não importa como o espaço produzido vai ser valorizado, o que importa é que ele vai ser valorizado de uma forma ou de outra, e esse valor já é intrínseco antes mesmo de sua produção enquanto materialidade.

A afirmação de que "o conceito de espaço reúne o mental e o cultural, o social e o histórico" (LEFEBVRE, 2006, p. 09) nos dá uma pista de que o tratamento do espaço como um sistema de valores pode ser uma via alternativa para a sua análise. Em outras palavras, o espaço não consiste apenas em valor comercial, vendável no mercado, mas em valor simbólico, sentimental, apreendido pelos sujeitos no decorrer de sua vida e no qual existe um laço de afetividade essencial à sua existência.

O espaço e sua produção têm de ser entendidos como um processo que ocorre na relação entre os sujeitos (indivíduos e coletividade) com valores, visões de mundo, com suas estruturas de relações sociais, econômicas, políticas e culturais. Assim sendo, a produção do espaço é feita através de um complexo movimento dialético entre a valorização subjetiva e a valorização objetiva dele.

Lefebvre (2006) em sua obra destacou a questão do indivíduo e do coletivo enquanto sujeitos na produção do espaço através de uma triplicidade: a prática espacial (espaço percebido), as representações do espaço (espaço concebido) e os espaços de representação (o espaço vivido). Assim, “o espaço social [e, sobretudo, o geográfico] incorpora atos sociais, os de sujeitos, ao mesmo tempo coletivos e individuais, que nascem e morrem, padecem e agem" (LEFEBVRE, 2006, p. 60).

Nessa perspectiva, o espaço se configura enquanto valor de uso e valor de troca, resultado de uma dialética que produz um espaço social de usos e simultaneamente um espaço abstrato de expropriação. É dessa forma que se configura a importância do espaço para Lefebvre (GOTTDIENER, 1993).

O espaço não é apenas econômico, onde as partes são intercambiáveis e têm valor de troca. $\mathrm{O}$ espaço não é apenas um instrumento político para homogeneizar todas as partes da sociedade. Ao contrário... O espaço continua sendo um modelo, um protótipo permanente do valor de uso que se opõe às generalizações do valor de troca na economia capitalista sob a autoridade de um Estado homogeneizador. $\mathrm{O}$ espaço é um valor de uso, mas ainda assim é tempo fundamental. O tempo desapareceu no espaço social da modernidade (LEFEBVRE, apud GOTTDIENER, 1993, p. 132). 
Valor de uso, valor de troca, valor criado, valor contido, valor do espaço e valor no espaço são os tipos de valores que compõem o espaço, fazendo dele um sistema de valores com relações mútuas com os sistemas de objetos e os sistemas de ações. Para isso,

(...) a sociedade como um todo atribui, a cada um dos seus movimentos, um valor diferente a cada fração do território e que cada ponto do espaço é solidário aos demais, em todos os momentos. A isso se chama totalidade do espaço (SANTOS, 1985, p. 64). (Grifo nosso).

Dessa forma, tratar o espaço como sendo, também, um sistema de valores é essencial para avançar na construção de uma teoria do espaço que o abarque enquanto totalidade. É dessa forma que o espaço banal, de tudo e de todos, de que fala Santos (2008a, 2008b), ganha mais vigor e concretude, pois os processos sociais, econômicos, políticos e culturais interagem simultaneamente na produção do espaço, sendo essa uma produção, ao mesmo tempo, subjetiva e objetiva.

\section{CONSIDERAÇÕES FINAIS}

O espaço enquanto categoria filosófica e conceito geográfico passou por várias reformulações conceituais no decorrer do processo histórico. A Geografia, sobretudo após sua autonomia como ciência no século XIX, engrossou o debate sobre a validade das perspectivas de pensar o espaço geográfico, ora tratado como paisagem, lugar, ora como território e como região.

$\mathrm{Na}$ segunda metade do século XX, o movimento de renovação da Geografia engendrou novas formas de se pensar o espaço, sobretudo baseado na perspectiva marxista, de base materialista e dialética, e na perspectiva humanista, pautado na corrente fenomenológica da filosofia.

Assim, desde os anos 1970 e, sobretudo, dos anos 1980, as duas correntes supracitadas travaram (e ainda travam) uma grande "batalha teórica" entre si a respeito da validade científica dos pressupostos teórico-metodológicos das concepções alheias, sempre tentando, de alguma forma, refutar as concepções contrárias sobre a questão do espaço.

Nesse período, a produção geográfica alcançou grande notoriedade no mundo acadêmico, sobretudo dentro das ciências sociais, principalmente com a perspectiva marxista, que foi predominante nessas décadas. Contudo, a partir da década de 1990, a perspectiva pautada na fenomenologia ganhou grandes proporções e teve um importante papel na influência dos trabalhos acadêmicos. Cada uma trabalha com uma concepção do espaço: a 
radical, com o espaço enquanto materialidade (objetividade); e a humanista, baseada no espaço vivido, dotado de significados e valores íntimos, das experiências cotidianas, do espaço enquanto extensão do corpo, mundo vivido (subjetividade).

Uma nova via de estudo, proposta aqui, que utiliza as concepções das correntes diferentes/divergentes da ciência geográfica, pode ser construída a partir da categoria valor, concebida aqui de forma ampla, ou seja, não apenas enquanto valor monetário, isto é, valor de troca, mas também como valor cultural, simbólico.

A proposta apresentada neste ensaio é de que a busca de uma teoria do espaço que contemple a Geografia pode ser encontrada a partir do tratamento do espaço como um sistema de valores, atrelado e intrínseco como o sistema de objetos e o sistema de ações.

Nesse contexto é preciso levar em consideração a reflexão colocada pelo viés humanista, pois a cultura, a religião, a música, o signo e uma gama de outras abordagens configuram um sistema de valores que passou a ser observado a partir dos estudos dessa corrente. Contudo, a produção radical também configura um sistema de valores dentro da Geografia, mas de um modo diferente, pois o valor que é abordado por essa perspectiva é o valor enquanto medida monetária, relacionado ao sistema produtivo capitalista e ao mercado. O valor na perspectiva radical se vincula à detenção de capital.

Assim, na concepção exposta aqui, com a inserção da categoria valor na conceituação do espaço, este é abarcado enquanto totalidade, enquanto objetividade e subjetividade, materialidade e imaterialidade. Dessa forma, o espaço banal, de tudo e de todos, é compreendido como uma relação mútua entre o que é coletivo e o individual (singular), um sistema de valores em permanente transformação.

\section{REFERÊNCIAS}

AUGÉ, Marc. Não-lugares: introdução a uma antropologia da supermodernidade. $2^{\mathrm{a}}$ ed. São Paulo: Papirus, 2001.

BOURDIEU, Pierre. Efeitos de Lugar. In. . (Org.) A miséria do Mundo. $5^{\mathrm{a}}$ ed. Petrópolis: Vozes, 2003, p. 159-166.

BUTTIMER, Anne. Apreendendo o dinamismo do mundo vivido. In: CHRISTOFOLETTI, Antônio (Org.). Perspectivas da Geografia. São Paulo: DIFEL, 1985, p.165-193.

CASTELLS, Manuel. A Questão Urbana. São Paulo: Ed. Paz e Terra, 2000.

DINIZ FILHO, Luis Lopes. Os Equívocos da Noção de 'Regiões que Exploram Regiões': Crítica ao Conceito de 'Transferência Geográfica de Valor' de Edward Soja. Revista do Departamento de Geografia (USP), São Paulo, v. 13, p. 165-186, 1999. 
CORREAA, Roberto Lobato. O espaço: conceito chave da geografia. In: CASTRO, Iná Elias de; et al. (Org.) Geografia: conceitos e temas. 10ª ed. São Paulo: Bertrand Brasil, 2007, p. $15-47$.

O Espaço Geográfico: algumas considerações. In: SANTOS, Milton (Org.). Novos Rumos da Geografia Brasileira. $2^{a}$ ed. São Paulo: Ed. Hucitec, 1988, p. 25-34.

CORRÊA, Roberto Lobato; ROZENDALH, Zeny. Geografia Cultural: introduzindo a temática, os textos e uma agenda. In: . (orgs) Introdução à Geografia Cultural. $2^{\mathrm{a}}$ ed. Rio de Janeiro, 2007, p. 9-18.

COSGROVE, Denis. A geografia está em toda parte: cultura e simbolismo nas paisagens humanas. In: CORREAA, Roberto Lobato; ROSENDAHL, Zeny (Orgs.). Paisagem, tempo e cultura. $2^{a}$ edição. Rio de Janeiro: Eduerj, 2004, p. 92-123.

DUARTE, Matusalém de Brito; MATIAS, Vandeir Robson da Silva. Reflexões sobre o espaço geográfico a partir da fenomenologia. Caminhos da Geografia, Uberlândia - Minas Gerais, v. 16, p. 190-206, 2005.

DUNCAN, James. A paisagem como sistema de criação de signos. In: CORREAA, Roberto Lobato; ROSENDAHL, Zeny (Orgs). Paisagens, textos e identidade. Rio de Janeiro, Eduerj, 2004. p, 91-132.

FREHSE, Fraya. Erving Goffman, sociólogo do espaço. Revista Brasileira de Ciências Sociais, v. 23, p. 155-166, 2008.

GODOY, Paulo Roberto Teixeira. A Produção do Espaço: uma reaproximação conceitual da perspectiva lefebvriana. Geousp, v. 23, p. 125-132, 2008.

HARVEY, David. Condição Pós-moderna. 17ª ed. São Paulo: Loyola, 2008.

A Justiça Social e a Cidade. São Paulo: Hucitec, 1980.

LEFEBVRE, Henri. Espaço e Política. Belo Horizonte: Ed. UFMG, 2008a.

O Direito à Cidade. $5^{\text {a }}$ ed. São Paulo: Ed. Centauro, 2008b.

. A Revolução Urbana. Belo Horizonte: Ed. UFMG, 2008c.

- A Produção do Espaço. Trad. Grupo "As (im)possibilidades do urbano na metrópole contemporânea". Do núcleo de Geografia Urbana da UFMG (do orginal: La producion de l' espace, $4^{\mathrm{a}}$ ed. Paris: Éditions Anthropos, 2000). Primeira versão início de 2006.

LENCIONI, Sandra. Região e Geografia. São Paulo: Edusp, 1999.

MORAES, Antonio Carlos Robert. Ideologias Geográficas. $4^{\mathrm{a}}$ ed. São Paulo: Hucitec/Annablume, 2002. 
MORAES, Antonio Carlos Robert; COSTA, Wanderley Messias da. Geografia Crítica. A Valorização do Espaço. São Paulo: Hucitec, 1984.

A Geografia e o Processo de Valorização do Espaço. In: SANTOS, Milton (Org.). Novos Rumos da Geografia Brasileira. $2^{a}$ ed. São Paulo: Hucitec, 1988, p. 111-130.

SANTOS, Milton. A Natureza do Espaço: técnica e tempo, razão e emoção. $4^{a}$ ed. São Paulo: Edusp, 2008a.

. Da Totalidade ao Lugar. São Paulo: Edusp, 2008 b.

. Metamorfoses do Espaço Habitado. $6^{\text {a }}$ ed. São Paulo: Edusp, 2008c.

. Por uma Geografia Nova. São Paulo: Edusp, 2006.

125-134, 2005.

Para que a geografia mude sem ficar a mesma coisa. RA'EGA, Curitiba, no . 9, p.

Espaço e Método. São Paulo: Nobel, 1985.

SCHAEFER, Fred K. O Excepcionalismo na Geografia: um estudo metodológico. Boletim de Geografia Teorética, Rio Claro, vol. 7, n 13, p. 5-37, 1977.

SMITH, Neil. A produção do espaço. In: Desenvolvimento Desigual. Rio de Janeiro: Bertrand Brasil, 1988, p, 109-147.

SOJA, Edward W. Geografias pós-modernas: a reafirmação do espaço na teoria social crítica. Rio de Janeiro: Zahar Editor, 1993.

TUAN, Yi-Fu. Geografia Humanística. In: CHRISTOFOLETTI, Antônio (Org.). Perspectivas da Geografia. São Paulo: DIFEL, 1985, p. 143-164.

Espaço e Lugar: a perspectiva da experiência. São Paulo: DIFEL, 1983. 